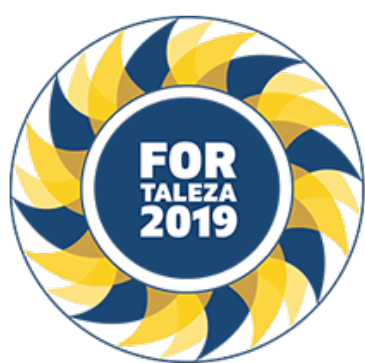

\title{
CHALLENGE IN THE DIAGNOSIS OF INFECTION IN HOSPITALIZED SYSTEMIC LUPUS ERYTHEMATOSUS PATIENTS: EVALUATION OF CLINICAL MARKERS, CRP, NEUTROPHIL-LYMPHOCYTE RATIO AND PLATELET-LYMPHOCYTE RATIO
}

\author{
JOANA STARLING CARVALHO (UFMG, BELO HORIZONTE, MG, Brasil), MARIA DAS GRAÇAS CARVALHO \\ (UFMG, BELO HORIZONTE, MG, Brasil), ANA JULIA FURBINO DIAS BICALHO (UFMG, BELO HORIZONTE, \\ MG, Brasil), GILDA APARECIDA FERREIRA (UFMG, BELO HORIZONTE, MG, Brasil)
}

\section{BACKGROUND}

The identification of infection in patients with Systemic Lupus Erythematosus (SLE) is a major challenge in clinical practice due to its high frequency, mortality and clinical manifestations that are confused with active disease. The objective of the present study was to evaluate clinical markers and the use of Creactive protein (CRP), neutrophil-lymphocyte (NLR) and platelet -lymphocyte (PLR) ratios in the diagnosis of infection in SLE patients.

\section{MATERIALS AND METHODS}

One hundred and four (104) hospitalizations of SLE patients were retrospectively evaluated and allocated into three groups, infected (26), infected and active (41) and isolated activity (37). They were compared in relation to clinical and laboratory variables. Infection has been defined as the presence of suggestive sings and symptoms plus at least one of the findings: suggestive image, positive culture or visible infection. Disease activity has been defined as modified SLEDAI 2K above four.

\section{RESULTS}

The frequency of fever, hypotension and tachypnea was higher in infected patients. C - reactive protein (CRP), NLR and PLR also differed among the groups with higher values being observed in the infected group, intermediary in the mixed group and lower in the group with isolated activity - CRP [56 (12 - 133) $\mathrm{mg} / \mathrm{dL}$ vs $26(3-59) \mathrm{mg} / \mathrm{dL}$ vs. $15(25-38) \mathrm{mg} / \mathrm{dL}, \mathrm{p}=0.002]$, NLR [7.9 (4.3 - 19.9) vs. 4.0 (1.9 - 8.5$)$ vs. 3.1 (2.1 - 4.9), p = 0.005], PLR [270 (146-616) vs. $227(138-520)$ vs. $134(104-250), p=0.025]$. Fever, tachypnea and PLR were independently associated with infection. The combined use of clinical and laboratory markers presented superior accuracy than isolated use for the diagnosis of infection in these patients.

\section{CONCLUSION}

The performance of NLR and PLR was inferior than CRP for the diagnosis of infection in patients with SLE. However, the combined use in the proposed flowchart has potential for future use in clinical practice, especially considering the satisfactory accuracy of the method, its low cost and accessibility. 